\title{
FOREWORD
}

\section{Affective Communication and Its Disorders}

The communicative and social value of affect may never be fully appreciated at a conscious level until it is compromised. In fact, much of our communication is carried out not through our words, but with the affective features that accompany those words: the prosody of our speech, our facial expressions, and body postures. Consider, for example, the disrespectful "tone of voice" that a teenager might use when speaking to a parent. (In the T.V. sitcom Seinfield, Jerry's mother refers to this as "the tone" and warns Jerry not to use it with her.) In the nonverbal domain, consider "the look" that some mothers use to control their children's behavior. Indeed, we can communicate "volumes" without speaking. In addition to our facial expressions, our body postures and the way we "carry" ourselves can communicate internal mood states such as excitement, defensiveness, and depression. For example, a quick look at a good friend may prompt us to ask, "Are you all right?" In all of these examples, of course, the affective communication is two-sided. One person is expressing a feeling or thought and the other is perceiving and interpreting the intent of these expressions.

So-called "average" people are capable not only of displaying a range of affective, mood, and thought states through their speech prosody, facial expressions, and body "language," they also appreciate societal rules for the appropriateness of what may be acceptably conveyed in particular situations. Tones of derision are not to be used with one's teachers. Frustrated "eye-rolling" in response to friends' statements about their religious beliefs would be unacceptable. Body language indicating impatience during a traffic cop's warning speech about exceeding the speed limit is probably a bad idea. Good communicators intuit or learn the "rules" of affective communication and apply them.

Some people are above average in their ability to communicate affect. Actors are masters of vocal, facial, and gestural nuances. "Con artists" and "stand-up" comedians succeed by virtue of both what they say and how they say it. We all know people who are masters of sarcasm in which the true message lies not in the face value of the words but in the manner they are uttered. Other people may be clever at manipulating aspects of their affective communication to hide profound inner feelings.

While there is admittedly a rather wide range of capacities for affective communication and underlying affective states in the "normal" population, acquired and developmental neurological disorders can cause noticeable impairment in these capacities. A well-recognized example is seen in the patient with the flattened facial and vocal affect caused by Parkinson's disease. Such patients may seem depressed or indifferent because of their inability to manipulate the expressive muscles of their face and the prosodic aspects of their speech. Patients with severe Parkinsonism may even appear demented because of their blank looks, the monotone quality of their speech, and stooped posture. One such patient of ours was labeled as "demented" by his doctor (admittedly he was difficult to test because of his motor problems), but his wife told me that he liked to go to the race track and was able to "handicap" the horses and riders and

Affective Communication: Characteristics, Disorders, and Clinical Implications. Editors in Chief, Nancy HelmEstabrooks, Sc.D., and Nan Bernstein Ratner, Ed.D.; Guest Editor, Colleen M. Karow, Ph.D. Seminars in Speech and Language, volume 24, number 2, 2003. ${ }^{1}$ Harold Goodglass Senior Investigator, Aphasia Research Center, Boston VA Healthcare System, Boston, Massachusetts. Copyright (C) 2003 by Thieme Medical Publishers, Inc., 333 Seventh Avenue, New York, NY 10001, USA. Tel: +1(212) 584-4662. 0734-0478,p;2003,24;02,065,066,ftx,en;ss100151a. 
often picked winners. In contrast, individuals with Alzheimer's disease (AD) who, indeed, are demented may appear cognitively brighter than they are because of relatively preserved affective communication. One of our AD patients who was very demented would respond to the question "How are you today?" with a snappy, convincing (but automatic) response "Right as rain!" Thus, we cannot base opinions regarding cognitive status entirely on the affective communication of neurologically impaired patients. Another lesson to be learned is that just because a patient with Parkinson's disease always "looks" depressed doesn't mean that he or she isn't really depressed. This caveat also applies to individuals who have had a right hemisphere stroke that affects their ability to demonstrate a wide range of emotions. They may not have the skills to express their feelings or they actually may feel quite indifferent to most things.

In contrast to patients who have difficulty with expression of affect, some patients with neurologic disorders have poor control over their emotions, i.e., emotional lability. This condition can be quite devastating, at the very least embarrassing. A patient of ours who was a wellknown physician before his strokes could not mention his family members without becoming so tearful that he could not continue speaking. He was highly distressed by his emotional lability which he understood and could call by name.

To remind us that affective communication is a two-way street, there are patients (particularly those with right hemisphere strokes and closed head injury) who are impaired in their ability to perceive and interpret affective communication. They may not understand sarcasm, joking, and teasing, and this inability can be problematic in their interpersonal exchanges of everyday life. We had a brain injured patient who could not reintegrate with his buddies at the neighborhood sports bar because he did not understand when he was being teased. Instead, he took comments at face value and became defensive.

Finally, it is important to consider the developmental problems that can influence individuals' ability to produce and interpret affective communication. Not uncommonly, children with learning disabilities have difficulties in such domains and their difficulties prevent successful socialization. Their use and interpretation of affective communication may be reduced or inappropriate, such as the hyperprosodic, sing-song speech of some developmentally disordered adolescents and teenagers. I once lived near a private residential school for such individuals and I could tell when teenagers from that school were present at the miniature-golf course by the tone and prosody of their speech and not by the content, which, of course, had to do with miniature golf.

These few examples underscore the importance of affective communication for both those with disorders in this realm and clinicians who must assess, diagnose, and treat these disorders. To bring readers up to date in this area, I asked Colleen Karow to serve as Guest Editor for an issue of Seminars in Speech and Language devoted to affective communication, its characteristics, disorders, and clinical implications. Dr. Karow has a strong clinical and research interest in this area and coauthored two excellent articles in this issue. At the same time, she recruited several other clinical researchers to write articles addressing other aspects of affective communication and its disorders. Together this team of authors has given us an issue of Seminars in Speech and Language that contains information of vital importance to our readers.

Nancy Helm-Estabrooks, Sc.D. Co-Editor in Chief ${ }^{1}$ 